\title{
Prevalence and Causes of Hyperuricemia in Children
}

Jatender Kumar ${ }^{1}$, Aarzoo Gupta ${ }^{2}$, Kapeel Dev ${ }^{3}$, Sameet Kumar ${ }^{4}$, Deepak Kataria ${ }^{5}$, Ambresha Gul ${ }^{6}$, Mohammed Abbas ${ }^{7}$, Amna Jamil ${ }^{1}$, Simra Shahid ${ }^{8}$, Sidra Memon ${ }^{9}$

1. Internal Medicine, Jinnah Postgraduate Medical Centre, Karachi, PAK 2. Internal Medicine, Vardhman Mahavir Medical College and Safdarjung Hospital, Faridabad, IND 3. Internal Medicine, Ghulam Muhammad Mahar Medical College, Sukkur, PAK 4. Internal Medicine, Chandka Medical College, Larkana, PAK 5. Internal Medicine, Shaheed Mohtarma Benazir Bhutto Medical University, Larkana, PAK 6. Internal Medicine, Peoples University of Medical and Health Sciences for Women, Nawabshah, PAK 7. Medicine, University of Louisville, Louisville, USA 8. Medicine, Jinnah Sindh Medical University, Karachi, PAK 9. Internal Medicine, Jinnah Sindh Medical University, Karachi, PAK

Corresponding author: Jatender Kumar, jatenderwadhwani@gmail.com

\section{Abstract}

\section{Introduction}

There are various factors responsible for hyperuricemia in children, however, there is extremely limited local data available. In this study, we aim to determine the causes and risk factors associated with hyperuricemia. This study will assist pediatric consultants to identify children who might be at risk of hyperuricemia and manage them accordingly.

\section{Methods}

This study was conducted in pediatric outpatient departments of various tertiary care hospitals from January 2018 to December 2019. Five thousand $(n=5000)$ children of either gender between the age group of 1-14 years, were enrolled in the study after informed consent from their parents. Uric acid levels were assessed by using the UASure blood uric acid monitoring handheld device.

\section{Results}

In our study, $\mathrm{n}=1301(26.02 \%)$ children had hyperuricemia. Hyperuricemia was more common in male compared to females $(65.49 \%$ vs. $34.51 \%$; p-value $<0.00001)$ and in older children $(9 \pm 2$ years vs. $7 \pm 3$; pvalue $<0.00001$ ). In hyperuricemia patients, the most common disorder was gastroenteritis $(23.98 \%)$, followed by respiratory infection (23.14\%) and asthma (15.45\%).

\section{Conclusion}

Hyperuricemia in children is very prevalent in the local setting. Patients with pre-existing conditions like congenital heart disease, asthma, epilepsy, and cancers should routinely be screened for hyperuricemia and managed accordingly to avoid long-term complications associated with hyperuricemia.

Review began 05/21/2021 Review ended 05/23/2021 Published 05/28/2021

\section{(c) Copyright 2021}

Kumar et al. This is an open access article distributed under the terms of the Creative Commons Attribution License CC-BY 4.0., which permits unrestricted use, distribution, and reproduction in any medium, provided the original author and source are credited.
Categories: Internal Medicine, Pediatrics

Keywords: hyperuricemia, uric acid, pediatrics, children, risk factors

\section{Introduction}

Hyperuricemia is a laboratory abnormality [1]. Considering its solubility, serum uric acid of greater than 7.0 $\mathrm{mg} / \mathrm{dL}$, is defined as hyperuricemia in adults [2]. But the important information that needs to be taken into consideration when defining hyperuricemia in the pediatric population is that uric acid levels change during development, increasing gradually from birth to the end of adolescence, sharply in males and slightly in females. Therefore, age and sex-related reference values for uric acid should be considered for defining hyperuricemia in children [3].

Some acute or chronic conditions that can be a major causative factor of increased uric acid in children and adolescents are Down's syndrome, congenital heart diseases, metabolic or genetic diseases, gastroenteritis, bronchial asthma, and malignant disorders. Obesity is one of the major causes of hyperuricemia because of its association with metabolic disorders and non-communicable diseases like hypertension, insulin resistance, dyslipidemia, and chronic kidney disease [1]. Literature has reported high prevalence in the obese population than the general population and proved a direct association of increased BMI with elevated uric acid [4]. Another study in China has shown a high prevalence of hyperuricemia in children of age 3-6 years, male gender, and a strong association with high diastolic blood pressure (DBP) and increased triglycerides concentration [5]. Hyperuricemia can occur as a side effect of several drugs like some antiepileptics, with valproate and phenobarbital being the commonest ones; thiazide diuretics, cyclosporine, theophylline, and 


\section{Cureus}

pyrazinamide have also been reported as the main causative factors, with their mechanism not fully understood [6].

Despite 35\% of the population less than 14 years of age in Pakistan, there is extremely limited data available on causes and risk factors associated with hyperuricemia [7]. In this study, we aim to determine the causes and risk factors associated with hyperuricemia. This study will assist pediatric consultants to profile children who might be at risk of hyperuricemia and manage them accordingly.

\section{Materials And Methods}

This study was conducted in the pediatric outpatient departments of various tertiary care hospitals from January 2018 to December 2019. Five thousand $(n=5000)$ children of either gender between the age group of 1 to 14 years, were enrolled in the study after informed consent from their parents. Children older than five years were explained the procedure and their ascent was taken. Uric acid levels were assessed by using the UASure blood uric acid monitoring handheld device. Participants were labeled with hyperuricemia based on Mayo Clinic Laboratories reference value (Table 1) [8].

\begin{tabular}{|c|c|}
\hline Age & Reference Value \\
\hline \multicolumn{2}{|l|}{ Male } \\
\hline $1-10$ years & $2.4-5.4$ mg/dL \\
\hline 11 years & $2.7-5.9$ mg/dL \\
\hline 12 years & $3.1-6.4$ mg/dL \\
\hline 13 years & $3.4-6.9 \mathrm{mg} / \mathrm{dL}$ \\
\hline 14 years & $3.7-7.4 \mathrm{mg} / \mathrm{dL}$ \\
\hline \multicolumn{2}{|l|}{ Female } \\
\hline 1 year & $2.1-4.9 \mathrm{mg} / \mathrm{dL}$ \\
\hline 2 years & $2.1-5.0 \mathrm{mg} / \mathrm{dL}$ \\
\hline 3 years & $2.2-5.1 \mathrm{mg} / \mathrm{dL}$ \\
\hline 4 years & $2.3-5.2 \mathrm{mg} / \mathrm{dL}$ \\
\hline 5 years & $2.3-5.3 \mathrm{mg} / \mathrm{dL}$ \\
\hline 6 years & $2.3-5.4 \mathrm{mg} / \mathrm{dL}$ \\
\hline 7-8 years & $2.3-5.5 \mathrm{mg} / \mathrm{dL}$ \\
\hline 9-10 years & $2.3-5.7 \mathrm{mg} / \mathrm{dL}$ \\
\hline 11 years & $2.3-5.8 \mathrm{mg} / \mathrm{dL}$ \\
\hline 12 years & $2.3-5.9 \mathrm{mg} / \mathrm{dL}$ \\
\hline$\geq 13$ years & $3.7-7.4$ mg/dL \\
\hline
\end{tabular}

TABLE 1: Mayo Clinic Laboratories reference value for hyperuricemia.

After testing for uric acid, participants were labeled as either a case or control group based on the presence or absence of hyperuricemia. Patient's characteristics such as age, gender, and detailed history included the presence of active respiratory or gastrointestinal infection, pre-existing conditions like asthma, congenital heart disease, epilepsy, and the nephrotic syndrome were noted in a self-structured questionnaire. Participant's BMI and blood pressure (BP) were checked and noted in a self-structured questionnaire.

Statistical analysis was done using the Statistical Package for the Social Sciences (SPSS) version 22.0 (IBM Corporation, Armonk, New York, United States). Continuous variables were analyzed via descriptive statistics and were presented as mean and standard deviation (SD) while categorical variables were presented by percentages and frequencies. Chi-square and t-test were used as appropriate. A p-value of less than 0.05 meant that there is a difference between the two groups and the null hypothesis is void. 


\section{Cureus}

\section{Results}

In our study, $\mathrm{n}=1301$ (26.02\%) children had hyperuricemia. Hyperuricemia was more common in males compared to their female counterparts $(65.49 \%$ vs. $34.51 \%$; p-value $<0.00001)$ and in older children $(9 \pm 2$ years vs. $7 \pm 3$; p-value $<0.00001)$. Participants with hyperuricemia also had significantly higher BMI, systolic blood pressure (SBP), and DBP (Table 2).

\begin{tabular}{|c|c|c|c|}
\hline Characteristics & Hyperuricemia $(n=1301)$ & Normouricemia ( $n=3699$ ) & P-value \\
\hline Age in years (Mean \pm SD) & $9 \pm 2$ & $7 \pm 3$ & $<0.0001$ \\
\hline Male (\%) & $852(65.49 \%)$ & $1871(50.59 \%)$ & $<0.00001$ \\
\hline BMI (Mean \pm SD) & $19.2 \pm 2.1$ & $16.9 \pm 1.8$ & $<0.00001$ \\
\hline SBP (Mean \pm SD) & $106.1 \pm 6.2$ & $99.5 \pm 4.9$ & $<0.00001$ \\
\hline DBP (Mean \pm SD) & $68.1 \pm 3.6$ & $62.1 \pm 3.1$ & $<0.00001$ \\
\hline Breastfed & 612 & 1802 & 0.29 \\
\hline
\end{tabular}

\section{TABLE 2: Characteristic of participants with hyperuricemia.}

DBP: Diastolic blood pressure; SBP: Systolic blood pressure.

In hyperuricemic patients, the most common disorder was gastroenteritis (23.98\%), followed by respiratory infection (23.14\%) and asthma (15.45\%). Other prominent disorders were nephrotic syndrome (5.38\%) and epilepsy (2.38\%) (Table 3).

\begin{tabular}{|c|c|c|c|}
\hline Disorders & Hyperuricemia $(n=1301)$ & Normouricemia ( $n=3699$ ) & P-value \\
\hline Gastroenteritis & $312(23.98 \%)$ & $306(8.27 \%)$ & $<0.00001$ \\
\hline Respiratory infections* & $301(23.14 \%)$ & $372(10.06 \%)$ & $<0.00001$ \\
\hline Asthma & 201 (15.45\%) & $281(7.60 \%)$ & $<0.00001$ \\
\hline Nephrotic syndrome & $70(5.38 \%)$ & $73(1.97 \%)$ & $<0.00001$ \\
\hline Epilepsy & $31(2.38 \%)$ & $19(0.51 \%)$ & $<0.00001$ \\
\hline Congenital heart disease ${ }^{\star \star}$ & $24(1.84 \%)$ & $27(0.73 \%)$ & 0.0005 \\
\hline Malignancy & $19(1.46 \%)$ & $21(0.57 \%)$ & 0.0034 \\
\hline Down syndrome & $17(1.31 \%)$ & $3(0.08 \%)$ & $<0.00001$ \\
\hline
\end{tabular}

\section{TABLE 3: Associated disorders with hyperuricemia.}

*Pneumonia, bronchitis, and respiratory syncytial infection.

${ }^{*}$ Ventricular septal defect, atrial septal defect, tetralogy of Fallot, patent foramen ovale, and transposition of great arteries.

\section{Discussion}

Our study demonstrated that the prevalence of hyperuricemia in children, coming to hospital due to any ailment, was $26 \%$. In another study, the prevalence of hyperuricemia in the adult population in Pakistan was 30.0\% [9]. In our study, hyperuricemia was more common in males and older children. Moreover, SBP, DBP, and BMI were higher in participants with hyperuricemia. In addition to this, some of the disorders more common in hyperuricemic participants were gastroenteritis (23.98\%), respiratory infections (23.14\%), and asthma (15.45\%). Among the prominent disorders, epilepsy and nephrotic syndrome were more common.

Several global studies have been conducted which are in line with this study. The incidence of gout was more common in males as compared to females [10]. Similarly, the study conducted by Kubota et al showed the presence of at least one underlying disorder among hyperuricemic patients [1]. Several factors have been 
identified which play a major role in causing hyperuricemia. Abnormalities during infancy or childhood in the metabolism of purine compounds have been shown to cause hyperuricemia [10]. Muscle exertion during glycogen storage diseases enhances the degradation of muscle purine nucleotides [11]. Moreover, Down syndrome and congenital heart diseases have also shown an association with hyperuricemia [12,13]. On the other hand, some of the acute disorders, including bronchial asthma, gastroenteritis, hemolytic anemia, and malignant disorders, also play an important role in causing hyperuricemia [14,15]. Feig and Johnson evaluated the positive correlation between the levels of uric acid, SBP, and DBP [16]. Similarly, our study also showed a positive correlation between them. In concordance with our study, hyperuricemia is considered to be an important risk factor for the development of diseases such as obesity, hyperlipidemia, and diabetes $[17,18]$. Hyperuricemia is a target of treatment as it increases the risk of mortality, particularly due to renal and cardiovascular diseases [19].

Since obesity is a major risk factor for hyperuricemia, lifestyle interventions including dietary modifications, physical activity, and behavioral changes to reduce weight are important. Moreover, xanthine oxidase inhibitors play an important role in treating several pediatric diseases. In addition to this, either used alone or in combination with enalapril, allopurinol helps in reducing BP in children with hyperuricemic hypertension [20]. On the other hand, uric acid oxidase (Rasburicase) results in a rapid decline in uric acid, compared to allopurinol [21]. However, these drugs should be used with caution, as they can cause severe skin side effects, including Stevens-Johnson syndrome, and hypersensitivity, etc. [22,23].

To the best of our knowledge, this is the first large-scale study that determines the prevalence of hyperuricemia in children in developing countries. Since the study was multicentric, our sample was diverse. However, a definite association between various diseases and hyperuricemia could not be established as the study was cross-sectional in nature. Another limitation is that the sample size was not taken from the general public, but from children coming to the outpatient department for various ailments, so care should be taken while inferring the calculated prevalence of hyperuricemia in the pediatric population to general population.

\section{Conclusions}

This study reflects the contribution of the various causes such as age, obesity, infections, and malignancy in causing hyperuricemia. These factors are particularly important concerning chronic diseases that cause hyperuricemia, starting early in childhood. There should be a more thorough investigation, and the treatment should be streamlined accordingly. Moreover, if diagnosed earlier, it results in improvement. Therefore, pediatricians should pay greater attention to hyperuricemia in clinical settings.

\section{Additional Information \\ Disclosures}

Human subjects: Consent was obtained or waived by all participants in this study. Jinnah Sindh Medical University issued approval JSMU/IRB-Ofc/2017-12-02. Animal subjects: All authors have confirmed that this study did not involve animal subjects or tissue. Conflicts of interest: In compliance with the ICMJE uniform disclosure form, all authors declare the following: Payment/services info: All authors have declared that no financial support was received from any organization for the submitted work. Financial relationships: All authors have declared that they have no financial relationships at present or within the previous three years with any organizations that might have an interest in the submitted work. Other relationships: All authors have declared that there are no other relationships or activities that could appear to have influenced the submitted work.

\section{References}

1. Kubota M: Hyperuricemia in children and adolescents: present knowledge and future directions . J Nutr Metab. 2019, 2019:3480718. 10.1155/2019/3480718

2. Neogi T: Clinical practice. Gout. N Engl J Med. 2011, 364:443-452. 10.1056/NEJMcp1001124

3. Wilcox WD: Abnormal serum uric acid levels in children . J Pediatr. 1996, 128:731-741. 10.1016/S00223476(96)70322-0

4. Kuwahara E, Murakami Y, Okamura T, et al.: Increased childhood BMI is associated with young adult serum uric acid levels: a linkage study from Japan. Pediatr Res. 2017, 81:293-298. 10.1038/pr.2016.213

5. Li N, Zhang S, Li W, et al.: Prevalence of hyperuricemia and its related risk factors among preschool children from China. Sci Rep. 2017, 7:9448. 10.1038/s41598-017-10120-8

6. Trück J, Laube GF, von Vigier RO, Goetschel P: Gout in pediatric renal transplant recipients . Pediatr Nephrol. 2010, 25:2535-2538. 10.1007/s00467-010-1599-6

7. Pakistan Population clock live - Countrymeters . Accessed: May 10, 2021: https://countrymeters.info/en/Pakistan.

8. Uric Acid, Serum - Mayo Clinic Laboratories, Pediatric Catalog . Accessed: May 10, 2021: https://pediatric.testcatalog.org/show/URIC.

9. Raja S, Kumar A, Aahooja RD, Thakuria U, Ochani S, Shaukat F: Frequency of hyperuricemia and its risk factors in the adult population. Cureus. 2019, 11:e4198. 10.7759/cureus.4198

10. Cameron JS, Moro F, Simmonds HA: Gout, uric acid and purine metabolism in paediatric nephrology . Pediatr Nephrol. 1993, 7:105-118. 10.1007/BF00861588 
11. Wilcox WD: Abnormal serum uric acid levels in children . J Pediatr. 1996, 128:731-741. 10.1016/s00223476(96)70322-0

12. Kubota M, Nagai A, Tang L, Tokuda M: Investigation on hyperuricemia in children with obesity or various pediatric disorders. Nucleosides Nucleotides Nucleic Acids. 2011, 30:1051-1059. 10.1080/15257770.2011.597370

13. Fuller RW, Luce MW, Mertz ET: Serum uric acid in mongolism. Science. 1962, 137:868-869. 10.1126/science.137.3533.868

14. Nagai A, Kubota M, Tang L, Adachi S, Usami I, Matsubara K: Hyperuricemia in pediatric malignancies before treatment. Nucleosides Nucleotides Nucleic Acids. 2011, 30:1060-1065. 10.1080/15257770.2011.591745

15. Kaplan BS, Thomson PD: Hyperuricemia in the hemolytic-uremic syndrome. Am J Dis Child. 1976, 130:854856. 10.1001/archpedi.1976.02120090064011

16. Feig DI, Johnson RJ: Hyperuricemia in childhood primary hypertension. Hypertension. 2003, 42:247-252. 10.1161/01.HYP.0000085858.66548.59

17. Ishizaka N, Ishizaka Y, Toda A, Tani M, Koike K, Yamakado M, Nagai R: Changes in waist circumference and body mass index in relation to changes in serum uric acid in Japanese individuals. J Rheumatol. 2010, 37:410-416. 10.3899/jrheum.090736

18. Kodama S, Saito K, Yachi Y, et al.: Association between serum uric acid and development of type 2 diabetes . Diabetes Care. 2009, 32:1737-1742. 10.2337/dc09-0288

19. Hsia S-H, Chou I-J, Kuo C-F, et al.: Survival impact of serum uric acid levels in children and adolescents . Rheumatol Int. 2013, 33:2797-2802. 10.1007/s00296-013-2808-y

20. Soletsky B, Feig DI: Uric acid reduction rectifies prehypertension in obese adolescents . Hypertension. 2012, 60:1148-1156. 10.1161/HYPERTENSIONAHA.112.196980

21. Pui C-H, Jeha S, Irwin D, Camitta B: Recombinant urate oxidase (rasburicase) in the prevention and treatment of malignancy-associated hyperuricemia in pediatric and adult patients: results of a compassionate-use trial. Leukemia. 2001, 15:1505-1509. 10.1038/sj.leu.2402235

22. Cheuk DK, Chiang AK, Chan GC, Ha SY: Urate oxidase for the prevention and treatment of tumor lysis syndrome in children with cancer. Cochrane Database Syst Rev. 2010, CD006945. 10.1002/14651858.CD006945.pub2

23. Somkrua R, Eickman EE, Saokaew S, Lohitnavy M, Chaiyakunapruk N: Association of HLA-B*5801 allele and allopurinol-induced Stevens Johnson syndrome and toxic epidermal necrolysis: a systematic review and meta-analysis. BMC Med Genet. 2011, 12:118. 10.1186/1471-2350-12-118 